\title{
Retraction Note: Recent progress on rubrene as active layer in organic field-effect transistors
}

\section{Wen Gu}

Published online: 18 August 2021

(C) Springer Nature B.V. 2021
The Editor-in-Chief and the Publisher have retracted this article. The article was accepted as part of a guest-edited special issue in Journal of Nanoparticle Research. Before the special issue was finalized, the Editor-in-Chief detected problems with editorial handling and peer review and decided not to proceed with the special issue Pinna et al. [1].

Post publication peer review found that this article is out of scope for the journal, which focuses on original contributions on nanoscale phenomena and processes, and does not meet the standards required by the journal.

The author has not responded to any correspondence from the publisher about this retraction.
The original article can be found online at https://doi.org/ 10.1007/s11051-020-04975-8.

\section{W. Gu $(\square)$}

College of Chemistry and Chemical Engineering,

Shanghai University of Engineering Science,

Shanghai 201620, China

e-mail:imgm90322@sina.cn

\section{References}

1. Pinna N, Clavel G, Roco MC (2020) The Journal of Nanoparticle Research victim of an organized rogue editor network! J Nanopart Res 22:376. https://doi.org/10.1007/ s11051-020-05094-0

Publisher's Note Springer Nature remains neutral with regard to jurisdictional claims in published maps and institutional affiliations. 